\title{
Gut Lesions in Fabry's Disease Without a Rash
}

\author{
D. M. FLYNN^, B. D. LAKE, C. B. BOOTHBY $\dagger$, and ELISABETH P. YOUNG \\ From The Hospital for Sick Children and the Institute of Child Health, Great Ormond Street, London
}

\begin{abstract}
Flynn, D. M., Lake, B. D., Boothby, C. B., and Young, E. P. (1972). Archives of Disease in Childhood, 47, 26. Gut lesions in Fabry's disease without a rash. Twin boys with Fabry's disease and 6 affected relatives were described. Limb pains and retinal vessel tortuosity were present but no patient had angiokeratomata. One boy had a severe enteropathy with small and large bowel involvement which was investigated. Thin-layer chromatography showed that excesses of ceramide diand trihexosides were excreted in the urine. Leucocyte a-galactosidase activity was measured: hemizygous males showed very low activity, while obligate and probable heterozygous females had values intermediate between those of the patients and the normal controls.
\end{abstract}

Fabry's disease first described by Anderson (1898) and Fabry (1898), is an X-linked disorder of lipid metabolism shown to be caused by a deficiency of ceramide trihexosidase (Brady et al., 1967). This deficiency results in the accumulation of ceramide trihexoside in many sites and produces a varying clinical picture with severe symptoms in some patients and no symptoms in others. The commoner clinical features are the rash of angiokeratoma corporis diffusum, extremity limb pains, renal failure, hypertension, and premature cerebrovascular disorders, but none is invariably present. Gut lesions are rare. It is rarely diagnosed in childhood in the absence of a family history or rash to suggest it. We present twin boys and 6 affected relatives with Fabry's disease, without a rash but with evidence of gut pathology. We also confirm that the diagnosis may be made by thin-layer chromatographic examination of urine sediment and by studying leucocyte $a$-galactosidase activity.

\section{Case Histories}

Twin boys of similar appearance were seen at age 10 years because of cramps in the legs for 5 years. The cramps were more frequent in hot weather and were inconstantly precipitated by exercise and pyrexia, exacerbated by the presence of the other twin, and relieved by hospitalization, and by cooling the legs. e.g. by placing them outside the bedclothes. Initially the cramps occurred every few weeks and lasted a few hours but became more frequent and more severe. Both boys had mild deafness due to secretory otitis. Stuttering

\footnotetext{
Received 17 August 1971.

*Present address: The Royal Free Hospital, Grays Inn Road, London.

tPresent address: The Radcliffe Infirmary, Oxford.
}

and educational handicaps were present. The birthweights were $2.3 \mathrm{~kg}$ (D., first twin) and $1.69 \mathrm{~kg}$ (A., second twin). At age 9 the IQ of D. was 76 and of A. was 58.

The twins were observed for five years and the cramps continued. No clinical or biochemical evidence was found to support diagnoses of peripheral neuropathy, hypoparathyroidism, hypokalaemia, or McArdle's syndrome, and therapy with salt, diphenhydramine, and calcium gluconate was ineffective. Though at age 8 years the weights and heights of both twins were on the 50th centile, their ranking gradually fell, and at age $14 \frac{1}{2}$ years $D$., the firstborn but now the smaller, was $142 \mathrm{~cm}$, and A. was $148 \mathrm{~cm}$ (3rd centile).

Patient A. (Twin II). At $14 \frac{1}{2}$ years of age, A. developed lethargy, pallor, and pyrexia, and lost weight from $39 \mathrm{~kg}$ (10th centile) to $31 \mathrm{~kg}$, and was admitted to hospital. For the first time the cramps were described as burning pains and were also present in the hands. Shortly after admission he began to pass two or three loose stools a day.

On examination (Fig. 1a) he was pale and pyrexial $\left(38.5^{\circ} \mathrm{C}\right)$ and complained of frequent limb pains. His lips were somewhat thickened and parted. There was slight palmar erythema but no rash. Careful examination before and after the diagnosis was established failed to reveal any evidence of angiokeratomata. There was no sexual hair and no penial or testicular enlargement. The retinal arteries showed marked tortuosity but the conjunctival vessels were normal. Slit-lamp examination showed a slight corneal haze. The blood pressure varied between 110-135/70-90 $\mathrm{mmHg}$ in the right arm and $105-115 / 79-90 \mathrm{mmHg}$ in the left arm. Tone, power, co-ordination, and sensation and deep reflexes were normal. There was no calf tenderness.

$\mathrm{Hb}$ was $10 \mathrm{~g} / 100 \mathrm{ml}$ and a film showed a slight anisocytosis. Total WBC $10,600 / \mathrm{mm}^{3}$ with $70 \%$ 

strongly positive to occult blood testing with $0.2 \%$ o-tolidine, and pus cells were visible microscopically. The serum vitamin A was $22 \mathrm{IU} / 100 \mathrm{ml}$ (normal 70200 ), and the serum folic acid $3.6 \mu \mathrm{g} / 100 \mathrm{ml}$ (normal 5.9-21). Jejunal and rectal biopsy results are described later. Ascorbic acid $100 \mathrm{mg}$ was given intravenously on two occasions. On the first occasion, $5 \mathrm{mg}$ was excreted in the urine in the next 3 hours; on the second occasion, $4 \mathrm{mg}$ was excreted (normal $50 \mathrm{mg}$ ). The blood urea and urinalyses were normal. A number of other investigations failed to reveal any abnormality including repeated stool cultures, motor nerve conduction time, and electromyogram, immunoglobulins, and sweat electrolytes. Urinary concentrations of thiamine and niacin were also normal.

Radiological investigations. Barium meal and followthrough showed clear evidence of dilatation and transverse barring in the jejunum with widening in the ileum (Fig. 2). Such appearances can be seen in coeliac disease, among other conditions. Barium enema showed initially that the distal half of the transverse colon and the descending colon were empty, narrow, tubular, and devoid of haustration, appearances that indicated a segmental colitis involving the transverse and descending colon (Fig. 3). The skeletal age measured later at a chronological age of $15 \cdot 1$ years was 12.5 years (Greulich and Pyle, 1959). This was more than 2 SD below the mean. There was absorption of the bone at the distal end of the distal phalanx of the index finger (Fig. 4) and loss of tufting in other distal phalanges.

Progress. Initially a diagnosis of ulcerative colitis was considered and he was treated for 10 days with sulphasalazine but became more febrile and developed a

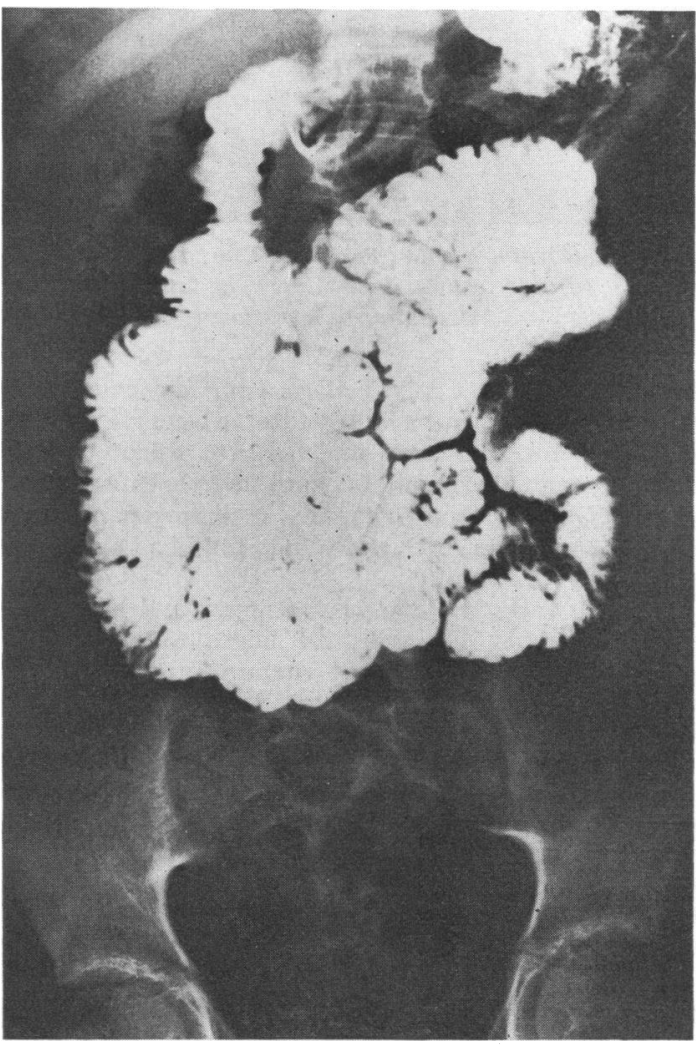

FIG. 2.-Barium meal and follow-through appearances in patient A. Note dilatation, flocculation, and coin-stacking appearances. 


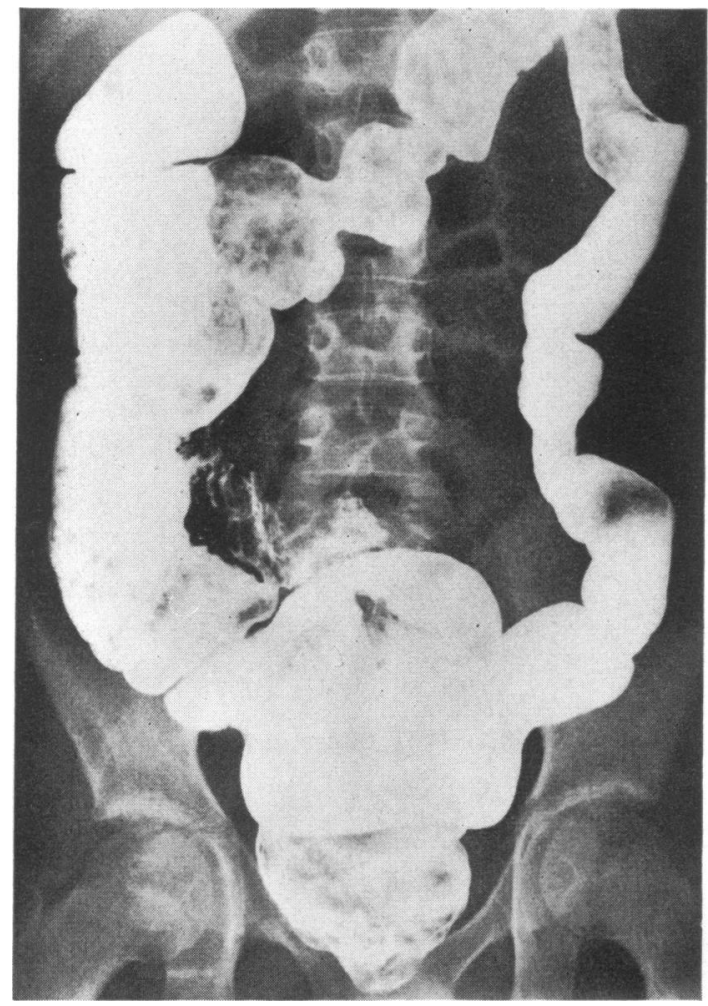

FIg. 3.-Barium enema appearances in patient $A$. Note narrow tubular colon, particularly in descending part, devoid of haustration.

sensitivity rash. Crohn's disease or an enteropathy with secondary burning foot syndrome were also thought possible. Intramuscular injections of thiamine alone caused some alleviation of both diarrhoea and limb pains. Other B group vitamins, including pantothenic acid, and vitamins $A, D$, and $C$, and folic acid were given orally and parenterally.

After 4 weeks the diarrhoea stopped and limb pains remitted. After 11 weeks, he began to gain weight and was discharged on oral vitamin supplements but later relapsed and again developed similar, though less severe leg pains which are still present.

Patient D. (Twin I). This twin had no episode of weight loss but was admitted for assessment at 143 years (Fig. 1b). His cramping limb pains were less severe than those of his brother. There was no sexual hair, no rash, and the facial appearance was similar to that in his twin. There was some palmar erythema. The conjunctival vessels were normal. The retinal vessels were tortuous, especially the veins, and slit-lamp examination showed a faint corneal haze. The blood pressure was $110 / 70 \mathrm{mmHg}$. He tended to walk with mild ankle inversion but there were no abnormal neurological findings.
There was no biochemical evidence of malabsorption. On a barium meal and follow-through the jejunum did not show such a clear-cut feathery pattern as usual and the longer folds were prominent on some films, but these features were of doubtful significance. His bone age was 2.5 years behind his chronological age and there were phalangeal changes similar to those of his brother. His pains decreased temporarily after injections of pantothenic acid.

As a result of a suggestion from Staff Nurse Ann Neville, the twins were then investigated for Fabry's disease. This diagnosis was confirmed by laboratory studies on jejunal mucosa, urine, and leucocytes.

\section{Family Studies}

Relatives from two generations were subsequently examined as shown in Fig. 5 and the Table. Of these two had abnormal eye signs. Only two relatives had both abnormal symptoms and signs, while in the definitely affected cousin, aged 4 years $(\operatorname{Pr} 11)$, there were neither abnormal signs nor symptoms. This boy subsequently developed typical limb pains. No relative showed or remembered having a rash. Relatives AI 6, and $\operatorname{Pr} 7-11$ were re-examined one year later and the previous findings were confirmed. In the second ascending generation there were five male children and

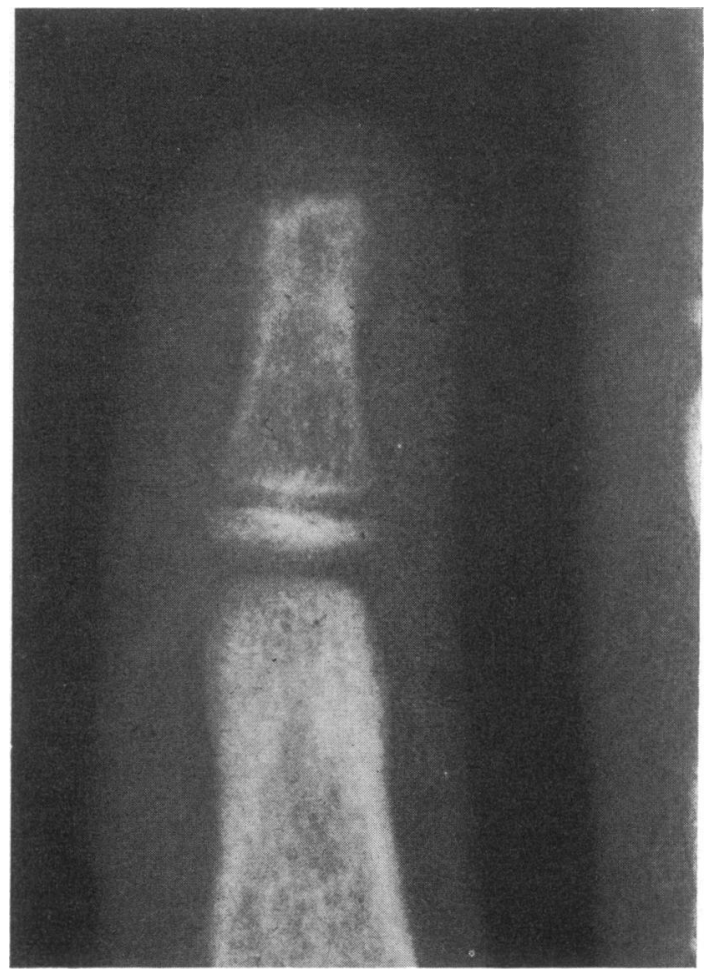

Fig. 4.-Terminal phalanx of index finger showing absorption of bone and loss of tufting, in patient $A$. 
TABLE

Family and Index Patient Studies

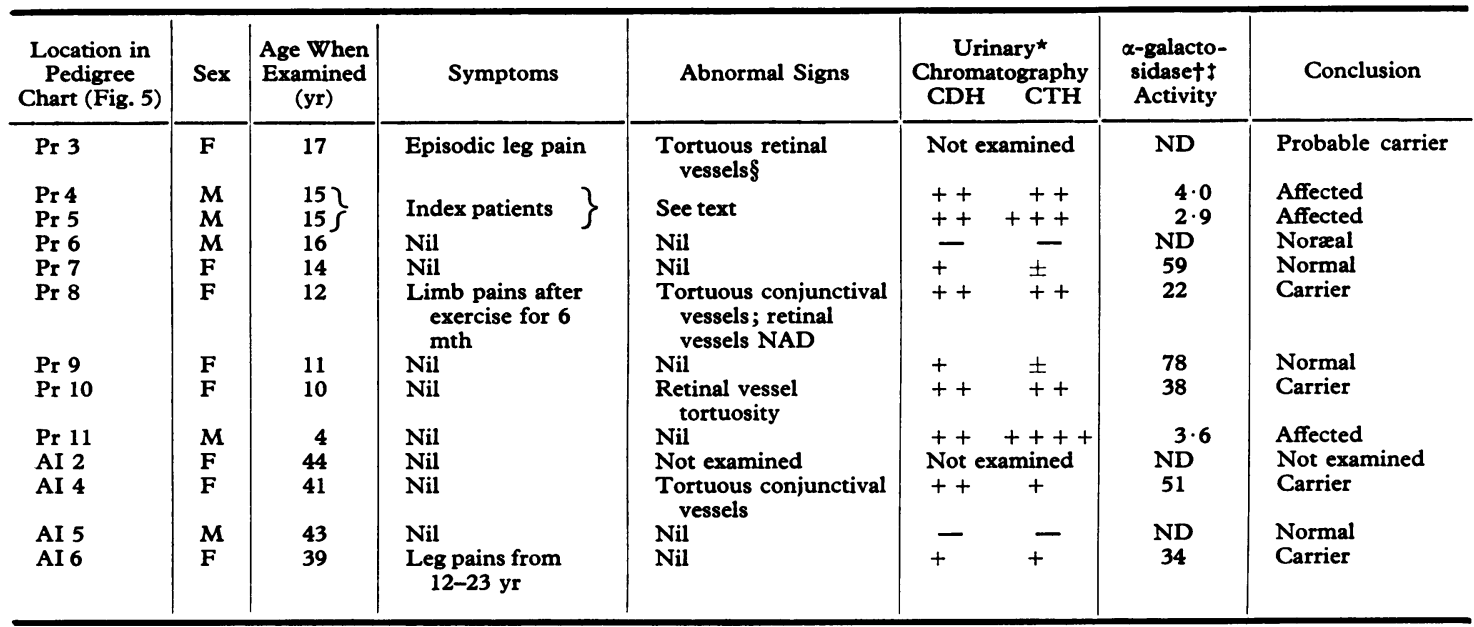

$\star \mathrm{CDH}, \mathrm{CTH}$, ceramide di- and trihexoside; the quantity of each present in the urine is arbitrarily graded from ( $\rightarrow$ ) (nil) through \pm to great ++++ .

$\dagger \alpha$-galactosidase activity: units expressed as $\mathrm{m} \mu$ 4-moles methyl umbelliferyl- $\alpha$-D-galactoside hydrolysed/mg protein per hour. Normal values (17 subjects, all ages) 56-120 units. Lowest normal adult $=73$ units.

$\mp \mathrm{ND}=$ Not done.

§This finding was reported by the patient's optician and has not yet been confirmed.

none is remembered as having leg pains or any other symptoms. It is probable that AII 11 developed a new mutation in view of the unaffected brothers AII $2-6$.

\section{Laboratory Studies}

Jejunal biopsy ( $\operatorname{Pr} 5)$. Prominent capillary loops were seen under the dissecting microscope. In paraffin sections the villous pattern was normal and there was no infiltrate in the lamina propria. Neurons in Meissner's plexus were enlarged and vacuolated, and stained positively with Sudan Black and Luxol Fast Blue. All blood vessels contained birefringent deposits of a sudanophilic, Luxol Fast Blue positive material, and the muscle cells in the muscularis mucosae also contained

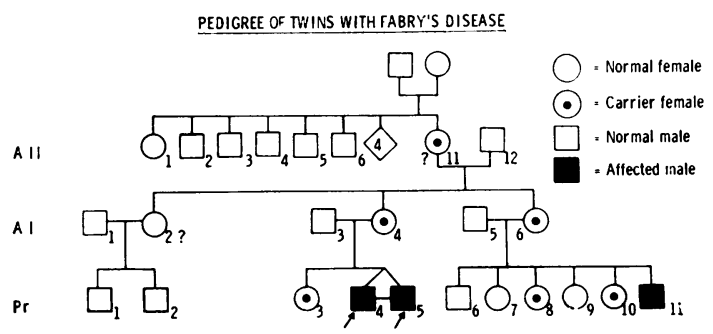

Fig. 5.-Pedigree of twins with Fabry's disease. Index patients indicated by arrows are $\operatorname{Pr} 4(D)$ and $\operatorname{Pr} 5(A)$. Carrier status of AI 2 and $A$ II 11 not determined. Arabic figures denote individuals in propositus (Pr) and first and second ascending ( $A I, A I I)$ generations. Other symbols are standard (Nelson et al., 1969). a similar substance. A biopsy of rectal mucosa showed similar, though less marked, changes.

Urine. Microscopical examination of urinary deposits was performed in members of both families (Table). The smear preparations were fixed in formaldehyde vapour and stained with PAS, Sudan Black, Toluidine Blue, and Luxol Fast Blue.

The spun deposits from the index patients contained numbers of cells which were coarsely granular, stained intensely with PAS, and were weakly sudanophilic. There was no metachromasia with Toluidine Blue and no staining with Luxol Fast Blue. Examination with polarized light showed the cells to be birefringent.

Deposits from AI 6 and her family contained numerous epithelial cells, and evaluation was impossible.

Aliquots $(100 \mathrm{ml})$ of 24-hour urine specimens were centrifuged, the supernatant decanted, and the deposit drained. The deposit was then twice extracted with chloroform-methanol $(2: 1 \mathrm{v} / \mathrm{v})$ and the extract evaporated to dryness under nitrogen. Final drying was accomplished under vacuum over phosphorus pentoxide. The extract was redissolved in a known volume of chloroform-methanol $(2: 1 \mathrm{v} / \mathrm{v})$. Chromatography using silica gel on glass plates was carried out using $20 \mathrm{ml}$ equivalents of urine. The solvent system was chloroform-methanol-water $(14: 5: 1 \mathrm{v} / \mathrm{v})$. The chromatogram was sprayed with diphenylamine to detect hexosides and the colour developed at $130^{\circ} \mathrm{C}$ (Fig. 6).

The results are summarized in the Table. The intensity of the bands is arbitrarily graded, nil to ++++ . Weak bands of various gangliosides were 


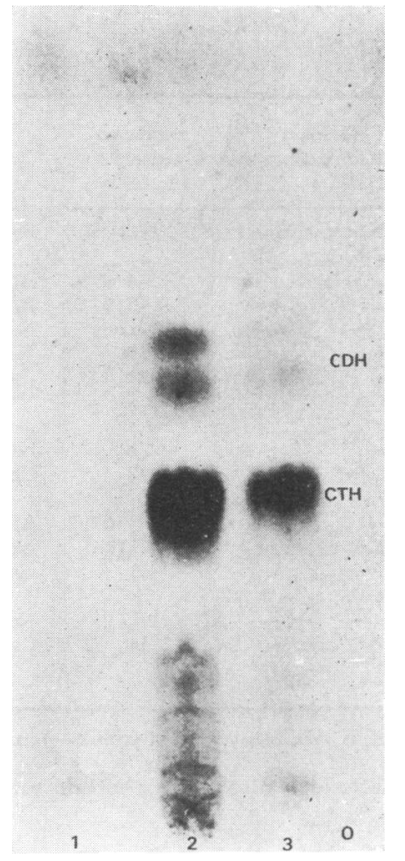

FIG. 6.-Thin-layer chromatogram of extract of deposit from $10 \mathrm{ml}$ urine. Lane 1-Normal control; Lane 2$A(\operatorname{Pr} 5)$; Lane 3-D $(\operatorname{Pr} 4) . \quad C D H=$ ceramide dihexoside; $C T H=$ ceramide trihexoside; and $O=$ origin.

also present in most samples from both families, with the exception of the normal father, AI 5.

Leucocyte enzyme studies. Leucocyte $\alpha$-galactosidase activity was assayed by the method described by Kint (1970), using 4-methyl umbelliferyl- $\alpha$-D-galactoside as substrate (Table). In 17 normal child and adult subjects, values between 56 and 120 units were recorded. The lower adult normal level recorded was 73 units. The three affected males had values of 4 units or less. Values for the two obligate heterozygote females and for two of the four possible heterozygote females studied were intermediate between the affected males and the lower limit of the normals.

Xga blood grouping and colour vision. Xga status was determined in $\operatorname{Pr} 4$ and 5, and 7-11 inclusive and in AI 4 and 6 . All were $\mathrm{Xg}^{\mathrm{a}}$ positive. Colour vision was tested in the same relatives and in the index patients and was normal in all (Opitz et al.s 1965).

Zygosity of twinning. The twins' mother had been told at birth that they were monozygous. Confirmation of the monozygosity was obtained by Dr. R. Sanger who found that each twin had the same status in each of 12 different blood groups. From these data and the fact that the twins were of like sex, it was calculated that the chances of dizygosity were only $P=0.026$.

\section{Discussion}

Our patients had the same slim build and stooping posture, with thickened, often parted lips previously described. It is thought that they also had the palmar erythemata noted by Johnston, Weller, and Warland (1968). The retinal and conjunctival vessel abnormalities, corneal haze, and limb pains are all characteristic of the condition. In our patients, interest centres principally on the presence of gut abnormalities, the absence of a rash, the urine chromatography results, and leucocyte a-galactosidase activity.

Gut abnormalities. Wise, Wallace, and Jellinek (1962) refer to diarrhoea in four patients with Fabry's disease including one of the first to be described (Günther, 1913). Their Case 1 had attacks of diarrhoea lasting a few months at ages 20 and 25 , and the rash had been noted at the age of 13 years. Sigmoidoscopy showed a friable mucous membrane, and barium enema revealed narrowing of the 'ilio-pelvic segment' of the colon and absent haustration.

Pompen and van Wayjen (1958) described two patients with diarrhoea. The first had periodic attacks of diarrhoea since age 15 years, passing up to seven watery stools a day. Sigmoidoscopy showed a granular mucosa, and barium enema revealed decreased haustration of the descending colon and parts of the transverse colon. The gut features resembled ulcerative colitis but the typical rash was present. There was no family history. Their second patient (unrelated) developed similar attacks of diarrhoea at age $\mathbf{4 0}$ years and died two years later. At necropsy, the colon had a firm wall, over $6 \mathrm{~cm}$ thick, and there were large necrotic hardenings. The upper small gut showed similar, but less severe changes. Typical skin lesions were present. No barium meal results were described.

Urbain, Philippart, and Peremans (1969) reported on a 23-year-old man with colitis, pyrexia, and hypo- $\gamma$-globulinaemia, in whom biopsy and urinary chromatography were characteristic of Fabry's disease. Barium studies of the stomach and small bowel showed no abnormalities. The transverse colon showed a complete absence of haustration, indicated by barium enema. Five years later there was no evidence of a rash. Campbell and Halford (1964) described a woman of 62 years with no rash, but with diarrhoea and a peripheral neuropathy.

Our patient, $\operatorname{Pr} 5$, resembles the first two mentioned above, with diarrhoea and similar barium enema appearances simulating ulcerative colitis; he differs in not having a rash, in presenting in the 
paediatric age group, and in the radiographic and biochemical evidence of malabsorption. The features on barium meal examination do not appear to have been reported previously. These consisted of dilatation and flocculation and coin-stacking appearance of the barium in the ileum and jejunum. The low folic acid and vitamin A levels confirmed malabsorption. A diagnosis of Fabry's disease should be considered when gut lesions are associated with tortuosity of retinal and conjunctival vessels, even if no rash is present. Fabry's disease is not mentioned in the differential diagnosis of malabsorption in standard texts (Cooke, 1968; Nelson, Vaughan, and McKay, 1969). Weight loss in several reported patients appeared before episodes of diarrhoea.

Absence of rash. The presence of excess ceramide trihexoside, and the deficiency of ceramide trihexosidase activity have become the hallmarks of Fabry's disease, rather than any clinical features, such as the rash. As ceramide trihexoside can be detected by thin-layer chromatography of the urine, identification of patients with Fabry's disease has been rendered much more straightforward. Cases other than the present family in which there was no rash have been described, but reports of the diagnosis of Fabry's disease in children without a rash and without a family history are rare.

In adults, Jensen (1966) described the necropsy findings of Fabry's disease in four brothers who died of uraemia in their 30's. Two had no rash, another developed a rash only in the year before his death, and in the fourth the presence or absence of a rash was not stated. Hamburger et al. (1964) described a mother and son with familial nephropathy, renal biopsy changes compatible with Fabry's disease, and tortuous retinal vessels, but no rash. Kemp (1967) described two brothers without a rash: one died at 37 with myocardial infarction and histological evidence of Fabry's disease, and another showed characteristic lesions on renal biopsy. Urbain et al. (1969) described a patient of 33 years without a rash or family history. Johnston et al. (1968) described adults and an adolescent without a rash, but with a family history, as did Fone and King (1964). Clarke et al. (1971) presented two unrelated adults with changes of Fabry's disease on renal biopsy, excess ceramide tri- and dihexoside in the urine, and deficient leucocyte $a$-galactosidase activity.

The above patients and the present family, all nearly or completely free from a rash, show that the diagnosis may have to be made without cutaneous evidence, though this may well appear later. Fabry's disease without a rash must be considered in the differential diagnosis of limb pains, arthritides, obscure pyrexia, and weight loss, hypertension and renal failure.

Age of onset of rash. The age of onset is of some importance to paediatricians. Wise et al. (1962) considered that, in the majority and perhaps all cases, the rash appeared before the age of 10 years, quoting two cases in which the rash appeared in infancy, and that systemic symptoms without a rash were rare. To ascertain the correlation between the age of onset of symptoms and the presence or absence of a rash at a stated age, 26 patients in whom these two ages were mentioned were collected from the literature (Curry and Fleisher, 1961; Wise et al., 1962; Fone and King, 1964; Dempsey et al., 1965; Rae, Lee, and Hopper, 1967; Johnston et al., 1968; Loeb et al., 1968). This method is subject to obvious limitations. Of 22 patients who developed limb pains at age less than 15 years, 11 had a period of one or more years without a rash. Limb pain without a rash is, therefore, a relatively frequent mode of presentation of Fabry's disease in the paediatric age group.

Delayed puberty. Neither of the index patients showed any evidence of puberty when examined at age 15 years, and both had the expected similar delay in bone age ( $2 \frac{1}{2}$ years). Puberty was therefore abnormally late (Marshall and Tanner, 1970). Adults with Fabry's disease are not reported as having short stature. Female carriers have no pubertal delay. Similar pubertal delay in males has been reported previously (Johnston et al., 1968).

Clinical features in females. Of the two adult females in our study, one had limb pains from age 12 to 23 and another showed tortuous conjunctival vessels. Variable penetrance in heterozygous females has been tentatively established, and occasionally this may be complete. Burda and Winder (1967) described a 47-year-old woman who died of renal and cardiac failure.

Urine studies. The microscopical examination of urinary sediment can, on occasions, be helpful and cells can be found which contain a substance with a staining characteristic expected for deposits of a ceramide trihexoside-cholesterol complex. However, if there are numerous epithelial cells, interpretation can be impossible.

Chromatographic examination of the extracted deposits gives a clear indication of the disease state. Here the amount of ceramide trihexoside is 
grossly raised and there is also an increased excretion of ceramide dihexoside. It is probable that the carrier state is indicated by slightly raised ceramide dihexoside and ceramide trihexoside levels (Philippart, Sarlieve, and Manacorda, 1969). The normal varies somewhat, but small amounts of cerebroside, ceramide dihexoside, and trihexoside may be excreted on occasions.

Other features. The significance of the abnormal vitamin $C$ studies remains obscure. Diminished sweating has been frequently described but our patients produced over $200 \mathrm{mg}$ sweat in response to the usual pilocarpine iontophoresis test, and presumably hypohydrosis does not become manifest until a later stage.

Pathogenesis. Involvement of peripheral nerves has been shown by Kocen and Thomas (1970). They found moderate depletion of myelinated nerves and deposits of glycolipid in perineural cells. There was no other evidence of peripheral neuropathy, and nerve conduction studies were normal. The loss of the smaller nerve fibres with sparing of the larger fibres may explain the sensory neuropathy in the presence of normal nerve action potentials.

The renal failure usually found in the later stages of the disease is probably caused by the lesions in the glomerulus (ballooning of glomerular epithelium) and in the tubules which interfere with renal function.

Ubiquitous deposition of ceramide trihexoside in smooth muscle cells accounts for the lesions in blood vessels giving rise to the skin lesions and for the later cardiac failure. The gastrointestinal symptoms may well be related to the deposits in the ganglion cells and muscle of the intestinal wall.
In common with certain other sphingolipidoses, Fabry's disease is characterized biochemically by the accumulation of a substance which is probably derived from the degradation of erythrocyte globoside (see below).

Kint (1970) has shown that leucocytes from patients with Fabry's disease are deficient in agalactosidase activity and this is confirmed in the patients presented here and by Clarke et al. (1971). This suggests that the terminal galactosyl residue of the ceramide trihexoside is linked through an $a$-galactosyl bond rather than through the $\beta$ linkage proposed by Sweeley, Snyder, and Griffin (1970). In our families, intermediate levels of $a$-galactosidase activity were found for the obligate heterozygote females and two of the four possible heterozygote females tested.

We are grateful to Dr. P. R. Evans for permission to publish these patients, to Dr. A. R. Chrispin for radiological studies, to Dr. A. D. Patrick for his advice on the enzyme determinations, and to Dr. R. Sanger for $\mathrm{Xg}^{\mathrm{a}}$ and other blood grouping studies.

One of us (E.P.Y.) is supported by a grant from the British Tay-Sachs Foundation.

\section{REFERENCES}

Anderson, W. (1898). A case of 'angeio-keratoma'. British fournal of Dermatology, 10, 113.

Brady, R. O., Gal, A. E., Bradley, R. M., Martensson, E., Warshaw, A. L., and Laster, L. (1967). Enzymatic defect in Fabry's disease: ceramidetrihexosidase deficiency. New England Fournal of Medicine, 276, 1163.

Burda, C. D., and Winder, P. R. (1967). Angiokeratoma corporis diffusum universale (Fabry's disease) in female subjects. American fournal of Medicine, 42, 293.

Campbell, A. M. G., and Halford, M. E. H. (1964). Syndrome of diarrhoea and peripheral nerve changes due to generalized vascular disease. British Medical fournal, 2, 1509.

Clarke, J. T. R., Knaack, J., Crawhall, J. C., and Wolfe, L. S. (1971). Ceramide trihexosidosis (Fabry's disease) without skin lesions. New England fournal of Medicine, 284, 233.

Cooke, R. E. (1968). Disorders of lipid metabolism. In The Biologic Basis of Pediatric Practice, p. 985 . Ed. by R. E. Cooke and S. Levin. McGraw-Hill, New York.
RBC globoside

$\beta$-galactosaminidase ( $A$ and $B$ forms)

Ceramide trihexoside

Ceramide trihexosidase

Lactosyl ceramide

Lactosyl ceramidase

Glucocerebroside

Glucocerebrosidase

Ceramide

\begin{tabular}{|c|c|c|c|}
\hline Abbreviations & $\begin{array}{l}\text { cer } \\
\text { glu } \\
\text { gal } \\
\text { gal }\end{array}$ & & $\begin{array}{l}\text { ceramide } \\
\text { glucose } \\
\text { galactose } \\
\text { N-acetylgalactosamine }\end{array}$ \\
\hline
\end{tabular}

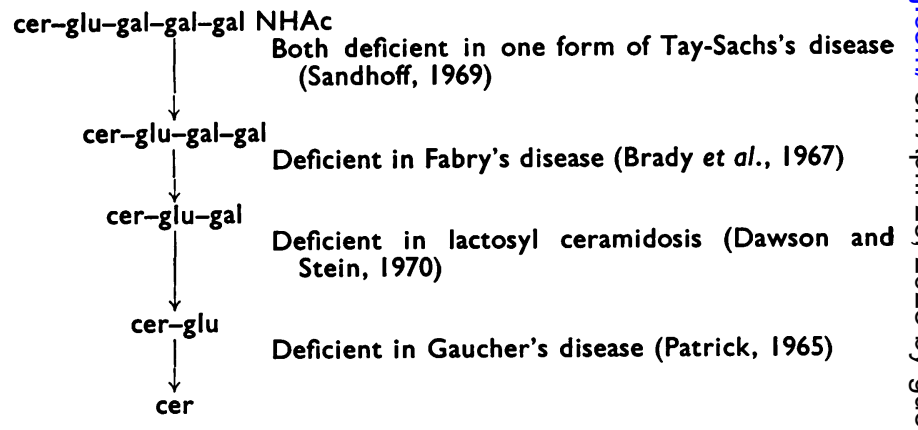

Both deficient in one form of Tay-Sachs's disease (Sandhoff, 1969)

Deficient in Fabry's disease (Brady et al., 1967)

ficient in lactosyl ceramidosis (Dawson and o 
Curry, H. B., and Fleisher, T. L. (1961). Angiokeratoma corporis diffusum: a case report. Fournal of the American Medical Association, 175, 864.

Dawson, G., and Stein, A. O. (1970). Lactosyl ceramidosis: catabolic enzyme defect of glycosphingolipid metabolism. Science, 170, 556.

Dempsey, H., Hartley, M. W., Carroll, J., Balint, J., Miller, R. E., and Frommeyer, W. B., Jr. (1965). Fabry's disease (angiokeratoma corporis diffusum): case report on a rare disease. Annals of Internal Medicine, 63, 1059.

Fabry, J. (1898). Ein Beitrag zur Kenntniss der Purpura haemorrhagica nodularis (Purpura papulosa haemorrhagica Hebrae). Archiv für Dermatologie und Syphilis, 43, 187.

Fone, D. J., and King, W. E. (1964). Angiokeratoma corporis diffusum (Fabry's syndrome). Australasian Annals of Medicine, $13,339$.

Greulich, W. W., and Pyle, S. I. (1959). Radiographic Atlas of Skeletal Development of the Hand and Wrist, 2nd ed. Stanford University Press, Stanford, California; Oxford University Press, London.

Günther, H. (1913). Cited by Wise et al. (1962). Anhydrosis und diabetes insipidus. Zeitschrift für klinische Medizin, 78, 53.

Hamburger, J., Dormont, J., de Montera, H., and Hinglais, N. (1964). Sur une singulière malformation familiale de l'epithélium rénal. Schweizerische Medizinische Wochenschrift, 94, 871.

Jensen, E. (1966). On the pathology of angiokeratoma corporis diffusum (Fabry). Acta Pathologica et Microbiologica Scandinavica, 68, 313.

Johnston, A. W., Weller, S. D. V., and Warland, B. J. (1968). Angiokeratoma corporis diffusum: some clinical aspects. Archives of Disease in Childhood, 43, 73.

Kemp, G. L. (1967). Fabry's disease involving the myocardium and coronary arteries without skin manifestations. Vascular Diseases, 4, 100.

Kint, J. A. (1970). Fabry's disease: $\alpha$-galactosidase deficiency. Science, 167, 1268.

Kocen, R. S., and Thomas, P. K. (1970). Peripheral nerve involvement in Fabry's disease. Archives of Neurology, 22, 81.
Loeb, H., Jonniaux, G., Tondeur, M., Danis, P., Grégoire, P. E., and Wolff, P. (1968). Étude clinique biochimique et ultrastructurelle de la maladie de Fabry chez l'enfant. Helvetica Paediatrica Acta, 23, 269.

Marshall, W. A., and Tanner, J. M. (1970). Variations in the pattern of pubertal changes in boys. Archives of Disease in Childhood, 45, 13.

Nelson, W. E., Vaughan, V. C., and McKay, R. J. (1969). Textbook of Paediatrics, 9th ed. Saunders, Philadelphia and London.

Opitz, J. M., Stiles, F. C., Wise, D., Race, R. R., Sanger, R., von Gemmingen, G. R., Kierland, R. R., Cross, E. G., and de Groot, W. P. (1965). The genetics of angiokeratoma corporis diffusum (Fabry's disease) and its linkage relations with the $\mathrm{Xg}$ locus. American fournal of Human Genetics, 17, 325.

Patrick, A. D. (1965). A deficiency of glucocerebrosidase in Gaucher's disease. Biochemical fournal, 97, 17c.

Philippart, M., Sarlieve, L., and Manacorda, A. (1969). Urinary glycolipids in Fabry's disease. Pediatrics, 43, 201.

Pompen, A. W. M., and van Wayjen, R. G. A. (1958). Enterocolitis als symptoom van angiokeratoma corporis diffusum (thesaurismosis Ruiter-Pompen-Wyers Kühnau). Nederlandsch Tijdschrift voor Geneeskunde, 102, 1941.

Rae, A. I., Lee, J. C., and Hopper, J., Jr. (1967). Clinical and electron miscroscopic studies of a case of glycolipid lipoidosis (Fabry's disease). Fournal of Clinical Pathology, 20, 21.

Sandhoff, K. (1969). Variation of $\beta-\mathrm{N}$-Acetylhexosaminidasepattern in Tay-Sachs disease. FEBS Letters, 4, 351.

Sweeley, C. C., Snyder, P. D., and Griffin, C. E. (1970). Chemistry of glycosphingolipids in Fabry's disease. Chemistry and Physics of Lipids, 4, 393.

Urbain, G., Philippart, M., and Peremans, J. (1969). Fabry's disease with hypogammaglobulinemia and without angiokeratomas. Archives of Internal Medicine, 124, 72.

Wise, D., Wallace, H. J., and Jellinek, E. H. (1962). Angiokeratoma corporis diffusum. Quarterly fournal of Medicine, 31, 177.

Correspondence to Dr. D. M. Flynn, The Royal Free Hospital, Grays Inn Road, London W.C.1. 